\title{
Amphetamine-Antagonistic Property of 4-Phenyltetrahydroisoquinoline: Effect on Noradrenaline Release in Spinal Cord Slices
}

\author{
Mitsutoshi Satoh', Shigeru Ohta ${ }^{2}$, Taku Nagao', Masaaki Hirobe ${ }^{2}$, Hideomi Fukuda ${ }^{3}$ and Hideki Ono ${ }^{1, *}$ \\ 'Department of Toxicology and Pharmacology, 'Department of Bioorganic and Medicinal Chemistry, \\ Faculty of Pharmaceutical Sciences, University of Tokyo. Tokyo 113, Japan \\ 'Department of Pharmacology, College of Pharmacy, Nihon University, Chiba 274, Japan \\ Received June 4,1992 Accepted July 23, 1992
}

\begin{abstract}
The amphetamine-related compounds methamphetamine, phenylethylamine and nomifensine increased the $\mathrm{K}^{+}$-evoked release of endogenous noradrenaline from rat spinal cord slices. 4Phenyl-1,2,3,4-tetrahydroisoquinoline (4PTIQ), which alone did not affect the $\mathrm{K}^{+}$-evoked release of noradrenaline, inhibited the noradrenaline-releasing effects of methamphetamine, phenylethylamine and nomifensine. 4PTIQ revealed a weak noradrenaline-uptake inhibitory effect, and the effect was weaker than those of desipramine and nomifensine. These results showed that 4PTIQ is an antagonist against the amine-releasing effects of amphetamines.
\end{abstract}

Keywords: 4-Phenyl-1,2,3,4-tetrahydroisoquinoline, Methamphetamine, Noradrenaline release, Spinal cord

The CNS-stimulant actions of amphetamines are considered to be due to their ability to release monoamines from monoaminergic nerve terminals $(1,2)$, inhibition of monoamine uptake (3) and inhibition of monoamine oxidase (MAO) (4). However, the mechanism of the CNS-stimulating action of amphetamines, especially their monoamine-releasing effect, is still unclear. The most widely accepted hypothesis is that amphetamine increases amine efflux by accelcrated cxchange diffusion $(5,6)$. By recording the spinal monosynaptic reflex (MSR) of spinalized rats, we have found that amphetamine-related compounds, methamphetamine. phenylethylamine and nomifensine (8-amino-2-methyl4-phenyl-1,2,3,4-tetrahydroisoquinoline), increase the amplitude of the MSR by releasing noradrenaline from the noradrenergic terminals of descending fibers (710), and have suggested that 4-phenyl-1,2,3,4-tetrahydroisoquinoline (4PTIQ) antagonizes the effects of these compounds by inhibiting their noradrenaline-releasing effects (9).

In the present study, to further elucidate the inhibitory effects of 4 PTIQ on noradrenaline release, we studied effects of 4PTIQ on the release of endogenous noradrenaline in rat spinal cord slices. The amphet-

\footnotetext{
* To whom correspondence should be addressed.
}

amine-related compounds methamphetamine, phenylethylamine and nomifensine facilitated the $\mathrm{K}^{+}$-evoked release of noradrenaline, and 4PTIQ inhibited the stimulatory effects of amphetamines on the release. The blocking effects of 4PTIQ and other compounds on the noradrenaline uptake were also evaluated.

\section{MATERIALS AND METHODS}

\section{Perfusion of rat spinal cord slices}

Male Wistar rats, aged 9-10 weeks (b.wt. 250-330 g), were sacrificed by decapitation. The lumbar enlargement of the spinal cord (L4-L5) was rapidly removed. The tissue was chopped into $300-\times 300-\mu \mathrm{m}$ slices with a Macllwain tissuc chopper and then dispersed in Krebs-Ringer bicarbonate buffer of the following composition: $118 \mathrm{mM} \mathrm{NaCl}, 4.7 \mathrm{mM} \mathrm{KCl}, 1.3 \mathrm{mM} \mathrm{CaCl}_{2}$, $1.2 \mathrm{mM} \mathrm{MgCl} 2,1.0 \mathrm{mM} \mathrm{NaH} \mathrm{PO}_{4}, 25 \mathrm{mM} \mathrm{NaHCO}$, $11.1 \mathrm{mM}$ glucose, $0.004 \mathrm{mM}$ EDTA and $0.11 \mathrm{mM}$ ascorbic acid. High $\mathrm{K}^{+}$solution was made by replacing equimolar $\mathrm{Na}^{+}$. The medium, $\mathrm{pH} 7.4$, was gassed

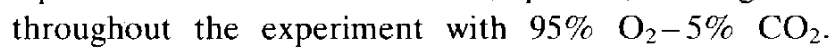
Slices of about $50-$ to $60-\mathrm{mg}$ wet tissue weight were placed in a perfusion chamber $(0.5-\mathrm{ml}$ internal volume $)$ and perfused with the medium $\left(37^{\circ} \mathrm{C}\right)$ for $60 \mathrm{~min}$ at a rate of $0.5 \mathrm{ml} / \mathrm{min}$. A single $8-\mathrm{min}(4-\mathrm{ml})$ sample was 
collected.

\section{Measurement of noradrenaline}

Noradrenaline in the perfusate was concentrated using alumina and determined by high performance liquid chromatography (HPLC) and electrochemical detection (ECD). The detection limit for noradrenaline was 50 fmol. Noradrenaline release was determined with 30 $\mathrm{mM}$ high $\mathrm{K}^{+}$at $76\left(\mathrm{~S}_{1}\right)$ and $176\left(\mathrm{~S}_{2}\right)$ min after the start of perfusion. The release of noradrenaline evoked by high- $\mathrm{K}^{+}$stimulation was estimated as described by Kamal et al. (2). Evoked release at the $S_{1}$ and $S_{2}$ periods of stimulation was estimated from the total amount minus basal release during stimulation. The test drugs were added to the perfusion medium $8 \mathrm{~min}$ before $S_{2}$ and during stimulation, and their effects were evaluated in terms of the ratio of the amounts evoked in the $S_{1}$ and $S_{2}$ periods of stimulation $\left(S_{2} / S_{1}\right)$.

\section{$l^{3}$ HINoradrenaline uptake}

The $\left[{ }^{3} \mathrm{H}\right]$ noradrenaline uptake experiment was performed with synaptosomal fractions of rat spinal cord. The lumbar segment of the spinal cord was isolated, weighed and homogenized gently in 10 volumes of 0.32 $M$ sucrose in a smooth glass homogenizer with a Teflon pestle (0.1- to $0.15-\mathrm{mm}$ clearance). Following centrifugation of the homogenate at $4^{\circ} \mathrm{C}$ for $10 \mathrm{~min}$ at $1000 \times$ $\mathrm{g}$, the supernatant fraction was centrifuged at $12,000 \times$ $g$ for $30 \mathrm{~min}$. The crude synaptosomal pellet $\left(\mathbf{P}_{2}\right)$ was gently resuspended in 5-10 volumes of Krebs-Ringer bicarbonate buffer. Uptake of $(-)\left[{ }^{3} \mathrm{H}\right]$ noradrenaline was allowed to proceed for $5 \mathrm{~min}$ at $37^{\circ} \mathrm{C}$, in $1 \mathrm{ml}$ (final volume) of incubation medium that had been prewarmed for $10 \mathrm{~min}$ at $37^{\circ} \mathrm{C}$ prior to the addition of synaptosomes. The medium contained pargyline (10 $\mu \mathrm{M})$ as a MAO inhibitor. $(-)\left[{ }^{3} \mathrm{H}\right]$ Noradrenaline, 13.7 $\mathrm{Ci} / \mathrm{mmol}$, was diluted, and the final concentration of $(-)\left[{ }^{3} \mathrm{H}\right]$ noradrenaline was $35 \mathrm{nM}$. Following incubation at $0^{\circ} \mathrm{C}$ and $37^{\circ} \mathrm{C}$ for $5 \mathrm{~min}$, the samples were diluted with $5 \mathrm{ml}$ of chilled $50 \mathrm{mM}$ Tris- $\mathrm{HCl}$ buffer ( $\mathrm{pH} 7.4$ ), filtered under vacuum on a Whatman GF/B manifold and then washed with a further $5 \mathrm{ml}$ of buffer. Prior to filtration, the filters had been soaked with polyethyleneimine $(0.1 \%)$ to lower the adsorption of $(-)\left[^{3} \mathrm{H}\right]$ noradrenaline to the filters. Radioactivity on the filters was counted in $5 \mathrm{ml}$ of Triton X-100 in toluene, containing 2,5-diphenyloxazol (PPO) and 1,4di[2-(5-phenyloxazolyl)]benzene (POPOP). All determinations were carried out in duplicate.

\section{Statistical analyses}

Numerical results are expressed as mean \pm S.E., and Duncan's New Multiple Range test was used to calcu- late statistical significance where appropriate. A P value less than 0.05 was considered to indicate a significant difference.

\section{Drugs}

Drugs used were (-)-noradrenaline hydrochloride (Alterenol, Sigma), pargyline hydrochloride (Sigma), 2phenylethylamine hydrochloride (Tokyo Kasei), desipramine hydrochloride (Ciba-Geigy), $S(+)$-methamphetamine hydrochloride (Dainippon Seiyaku), nomifensine maleate (Hoechst), $(-)\left[{ }^{3} \mathrm{H}\right]$ noradrenaline (specific activity, $13.7 \mathrm{Ci} / \mathrm{mmol}$; New England Nuclear) and 4-phenyl-1,2,3,4-tetrahydroisoquinoline (4PTIQ) hydrochloride. 4PTIQ hydrochloride was synthesized (mp. of $217-219^{\circ} \mathrm{C}$ ), and its purity was more than $99.7 \%$ by elemental analysis.

\section{RESULTS}

Effects of amphetamine-related compounds on $K^{+}$. evoked relase of endogenous noradrenaline

In the control experiment, the releases induced by 30 $\mathrm{mM} \mathrm{K}^{+}$from rat spinal cord slices, $S_{1}$ and $S_{2}$, were $1.41 \pm 0.22$ and $1.11 \pm 0.23 \mathrm{pg} / \mathrm{mg} / \mathrm{min}(\mathrm{n}=10)$, respectively. This high- $\mathrm{K}^{+}$-evoked release of endogenous noradrenaline was $\mathrm{Ca}^{2+}$-dependent.

Exposure of the spinal cord to methamphetamine (3 $\times 10^{-6} \mathrm{M}$ ), phenylethylamine $\left(10{ }^{5} \mathrm{M}\right)$ or nomifensine $\left(10^{-5} \mathrm{M}\right.$ ) increased the $\mathrm{S}_{2}$ (Figs. $1 \mathrm{C}$ and 2) without affecting the spontaneous outflow of noradrenaline. The ratio $S_{2} / S_{1}$ in the control experiment was not significantly different from unity. However, the $S_{2} / S_{1}$ ratios of methamphetamine $\left(3 \times 10^{-6} \mathrm{M}\right)$, phenylethylamine $\left(10{ }^{5} \mathrm{M}\right)$ and nomifensine $\left(10^{-5} \mathrm{M}\right)$ were $2.39 \pm 0.20$, $2.62 \pm 0.48$ and $1.81 \pm 0.31$, respectively, being significantly different from that of the control (Figs. 1C and 2). Pargyline $\left(10^{-5} \mathrm{M}\right)$ and deprenyl $\left(10^{-5} \mathrm{M}\right)$, both MAO inhibitors, and desipramine $\left(10^{-5} \mathrm{M}\right)$, an uptake inhibitor, did not increase the $S_{2} / S_{1}$ ratio (Fig. 2). 4PTIQ $\left(10^{-5} \mathrm{M}\right)$ alone added $20 \mathrm{~min}$ before $\mathrm{S}_{2}$ did not affect the $S_{2} / S_{1}$ ratio (1.16 \pm 0.15 ) (Fig. 2). 4PTIQ $\left(10^{-5} \mathrm{M}\right)$ added along with amphetamine-related compounds significantly reduced the $S_{2} / S_{1}$ ratios of methamphetamine $(0.92 \pm 0.11)$, phenylethylamine $(1.18 \pm 0.14)$ and nomifensine $(0.85 \pm 0.06)$ (Figs. 1D and 2).

Effects of amphetamine-related compounds on $\left.{ }^{3} \mathrm{H}\right]$ noradrenaline uptake into rat spinal cord synaptosomes

The inhibitory effects on $\left[{ }^{3} \mathrm{H}\right]$ noradrenaline uptake were compared among desipramine, nomifensine, methamphetamine, phenylethylamine and 4PTIQ. The order of potency in inhibiting $\left[{ }^{3} \mathrm{H}\right]$ noradrenaline uptake 

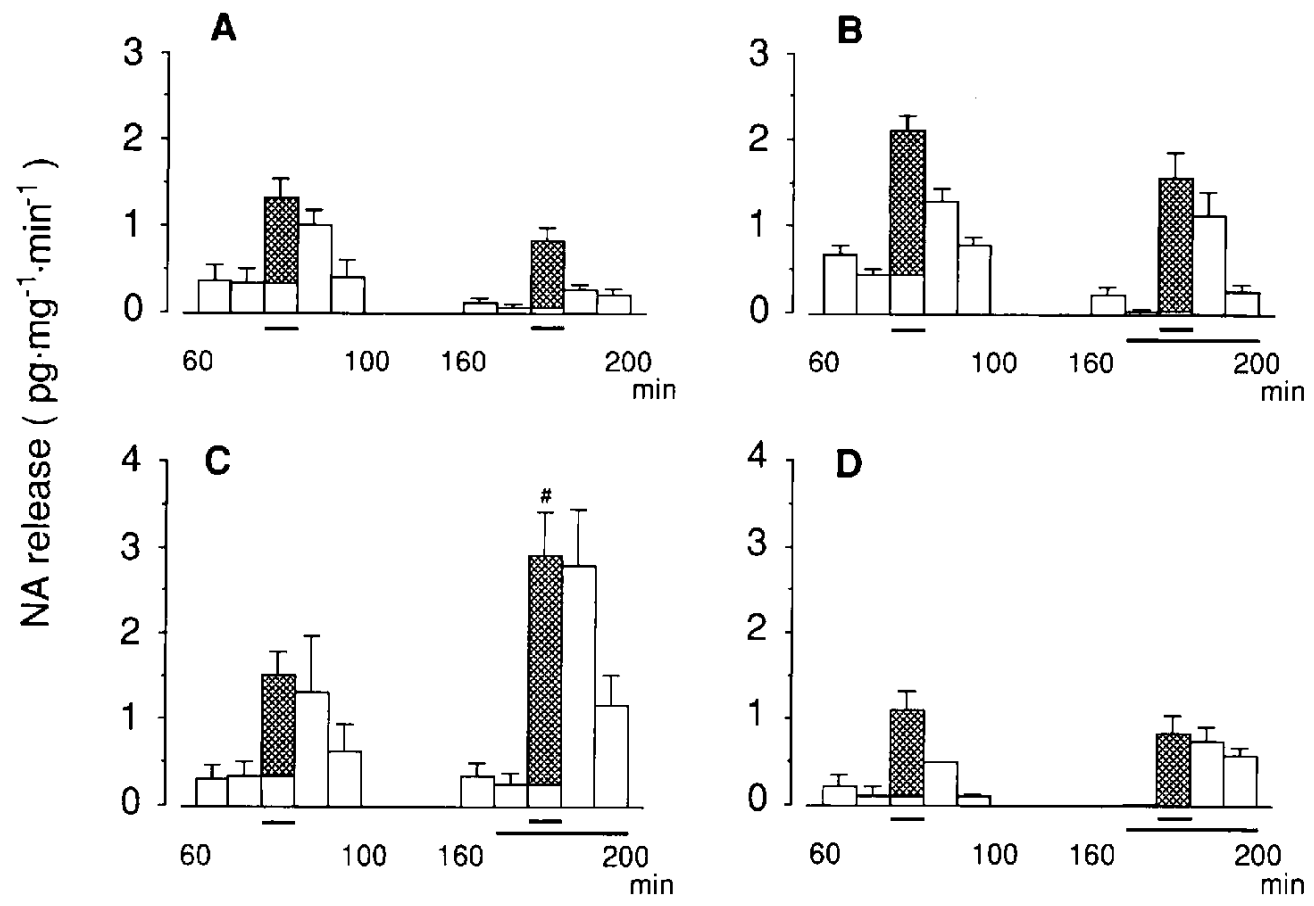

Fig. 1. Effects of 4 PTIO and methamphetamine on $\mathrm{K}^{+}$-evoked release of endogenous noradrenaline and inhibitory effects of 4PTIQ on facilitation of $\mathrm{K}^{+}$-evoked noradrenaline release from rat spinal cord slices induced by methamphetamine. High- $\mathrm{K}^{+}$-stimulation was performed by increasing the $\mathrm{KCl}$ concentration of the perfusion medium to $30 \mathrm{mM}$ for 8 min at $76\left(S_{1}\right)$ and $176\left(S_{2}\right)$ min after the start of perfusion (short line). The efflux of endogenous noradrenaline was measured by HPLC with electrochemical detection. Ordinates represent the overflow of endogenous noradrenaline in the perfusate for each 8-min sample. Abscissae represent the time after the spinal cord slices had been placed in the perfusion chamber. Drugs were applied to the perfusion medium $8 \mathrm{~min}$ before $S_{2}$ on the abscissae (long line). A, Control; B, $10^{-5} \mathrm{M}$ 4PTIQ; C, $3 \times 10^{-6} \mathrm{M}$ methamphetamine; D, $10^{-5} \mathrm{M} 4 \mathrm{PTIQ}+3 \times 10^{-6} \mathrm{M}$ methamphetamine. Each value represents the mean \pm S.E.M. of $3-6$ experiments. $: \mathrm{P}<0.05$, corresponding column.

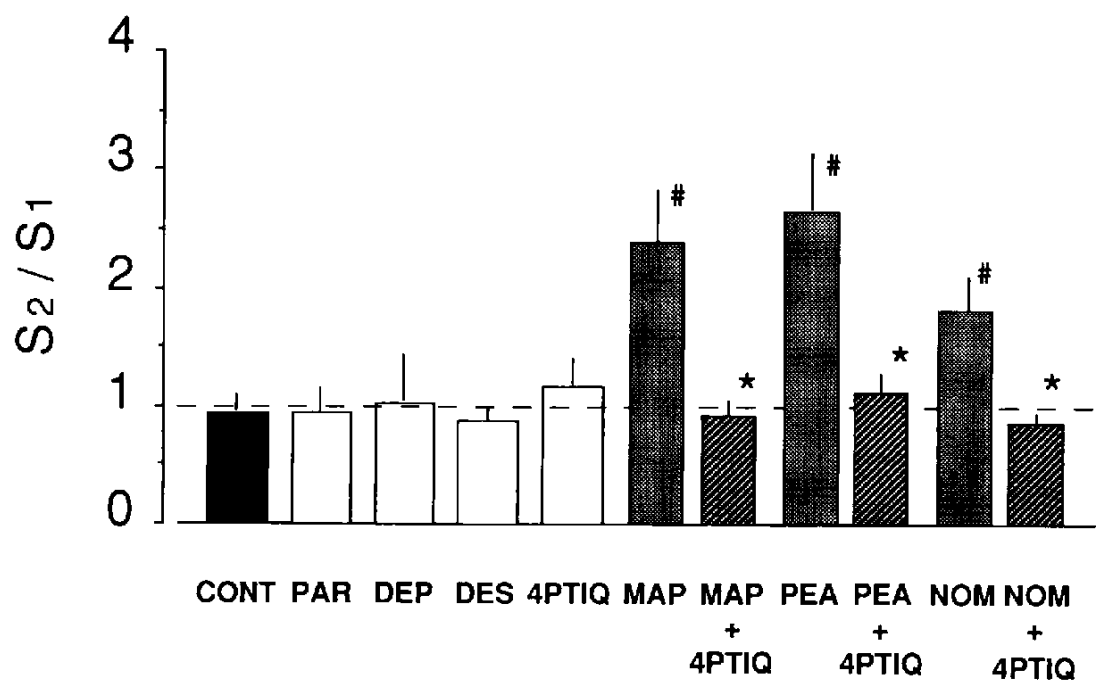

Fig. 2. Effects of various drugs on $\mathrm{K}^{\dagger}$-evoked release of endogenous noradrenaline and inhibitory effects of $4 \mathrm{PTIO}$ on facilitation of $\mathrm{K}^{\prime}$-evoked noradrenaline release from rat spinal cord slices induced by stimulants. High- $\mathrm{K}^{+}$-stimulation was performed by increasing the $\mathrm{KCl}$ concentration of the perfusion medium to $30 \mathrm{mM}$ for $8 \mathrm{~min}$ at $76\left(\mathrm{~S}_{1}\right)$ and $176\left(\mathrm{~S}_{2}\right) \mathrm{min}$ after the start of perfusion (shown in Fig. 1). The ordinate represents ratios of noradrenaline released in the $S_{1}$ and $S_{2}$ periods of stimulation. CONT, control; PAR, $10^{-5} \mathrm{M}$ pargyline; DEP, $10{ }^{5} \mathrm{M}$ deprenyl; DES, $10^{-5} \mathrm{M}$ desipramine; $10^{-5}$ $\mathrm{M}$ 4PTIQ; MAP, $3 \times 10^{6} \mathrm{M}$ methamphetamine; PEA, $10^{-5} \mathrm{M}$ phenylethylamine; NOM, $10^{5} \mathrm{M}$ nomifensine. Each value represents the mean \pm S.E.M. of $3-6$ experiments. ${ }^{\sharp}: \mathrm{P}<0.05$ vs. control. ${ }^{*}: \mathrm{P}<0.05$ vs. corresponding column. 
Table 1. Inhibition of $\left[{ }^{3} \mathrm{H}\right]$ noradrenaline uptake into synaptosomes by drugs

\begin{tabular}{lc}
\hline Drugs & $\begin{array}{c}{\left[{ }^{3} \mathrm{H}\right] \text { Noradrenaline uptake }} \\
\mathrm{IC}_{50}(-\log \mathrm{M})\end{array}$ \\
\cline { 2 - 2 } Desipramine & $8.02 \pm 0.07$ \\
Nomifensine & $7.31 \pm 0.09$ \\
Phenylethylamine & $7.01 \pm 0.19$ \\
Methamphetamine & $6.94 \pm 0.04$ \\
4PTIQ & $6.10 \pm 0.11$ \\
\hline
\end{tabular}

Spinal cord synaptosomes were incubated in the presence of the test drug for $10 \mathrm{~min}$ before the addition of $\left[{ }^{3} \mathrm{H}\right]$ noradrenaline $(35$ $n M)$. Uptake was terminated after 5 min by addition of ice-cold Krebs-Ringer buffer, followed by rapid filtration. Specific uptake of $\left[{ }^{3} \mathrm{H}\right]$ noradrenaline into synaptosomes was estimated from the difference between the uptake at $37^{\circ} \mathrm{C}$ and that at $0^{\circ} \mathrm{C}$. The $\mathrm{IC}_{50}$ value is expressed as the mean \pm S.E.M. of 3-5 experiments, each performed in duplicate.

was desipramine $>$ nomifensine $>$ phenylethylamine $=$ methamphetamine $>4$ PTIQ (Table 1). 4PTIQ was thus less potent than the other compounds.

\section{DISCUSSION}

Terminals of noradrenergic neurons in the ventral horns of the spinal cord originate in the brain stem, e.g., the locus ceruleus (11-13). Methamphetamine, phenylethylamine and nomifensine release noradrenaline from the terminals of noradrenergic descending fibers, and the released noradrenaline increases the excitability of motoneurons and spinal reflex potentials via alpha ${ }_{1}$-adrenoceptors $(9,14-16)$. On the basis of recordings made of spinal reflex potentials, we have suggested that 4 PTIQ blocks the noradrenaline-releasing effects of methamphetamine, phenylethylamine and nomifensine, and consequently antagonizes the MSRstimulating effects of amphetamines (9).

In the present study, methamphetamine, phenylethylamine and nomifensine enhanced the $\mathrm{K}^{+}$-evoked release of noradrenaline. However, pargyline and deprenyl, MAO inhibitors, and desipramine, an amine uptake inhibitor, did not affect the $S_{2} / S_{1}$ ratio of the $K^{+}$evoked noradrenaline release. These results suggest that effects other than inhibition of MAO and its uptake enhanced the release of noradrenaline. Stamford et al. (17) showed that uptake inhibitors stimulate the overflow of dopamine in the nucleus accumbens during electrical stimulation of the medial forebrain bundle, without blocking the reuptake of dopamine after cessation of stimulation. They concluded that some uptake blockers can directly increase the release of dopamine in a manner unrelated to uptake blockade. Some other studies have shown dissociation of the actions of uptake blockers on dopamine release and dopamine uptake (3, 18). The present results, showing that methamphetamine, phenylethylamine and nomifensine increased the $\mathrm{K}^{+}$-evoked release of noradrenaline, resemble these of Stamford et al. (17).

4PTIQ, which alone did not increase the release of noradrenaline, reduced the increase in the $\mathrm{K}^{+}$-evoked release of noradrenaline produced by amphetamines. Thus the present results directly demonstrated the inhibitory effects of 4PTIQ on the noradrenaline-releasing effects of amphetamines, and confirmed the results obtained in reflex experiments. Desipramine $\left(10{ }^{6} \mathrm{M}\right)$ added along with methamphetamine significantly did not affect the $S_{2} / S_{1}$ ratio of methamphetamine. This fundamentally supports the possibility that the inhibiting effect of 4PTIQ on the noradrenaline-releasing effects of methamphetamine is different from the noradrenaline uptake-blocking effects of uptake-blockers such as desipramine.

4PTIQ showed a weak inhibitory effect on noradrenaline uptake into spinal cord synaptosomes, and the effect was weaker than those of all the other compounds tested. Thus, the inhibitory effects of $4 \mathrm{PTIQ}$ on amphetamines may not be due to the uptake-blocking effects of this compound. In addition, 4PTIQ blocked the noradrenaline-releasing effect of nomifensine, which is a strong amine uptake inhibitor (19).

The present results showed that 4PTIQ antagonizes the noradrenaline-releasing effects of methamphetamine, phenylcthylamine and nomifensine in spinal cord slices. Preliminary data obtained in a behavioral study showed that 4PTIQ (s.c or microinjected into the nucleus accumbens) inhibited the ambulation-stimulating effect and dopamine-releasing effects of methamphetamine measured by the microdialysis method. Thus, 4PTIQ is considered to be a compound which has antagonistic effects against amphetamines and may be a useful tool for elucidating the monoamine-releasing mechanism of amphetamines.

\section{Acknowledgments}

This work was supported in part by a Grant-in-Aid for Scientific Reserach from the Ministry of Education, Science and Culture of Japan. We are grateful to Hoechst for supplying nomifensine maleate.

\section{REFERENCES}

1 Azzard, A.J. and Rutledge, C.O.: Selectivity of release of norepinephrine, dopamine and 5-hydroxytryptamine by amphetamine in various regions of rat brain. Biochem. Pharmacol. 22, $2801-2813$ (1973)

2 Kamal, L.A., Arbilla, S. and Langer, S.Z.: Presynaptic modu- 
lation of the release of dopamine from the rabbit caudate nucleus: Differences between electrical stimulation, amphetamine and tyramine. J. Pharmacol. Exp. Ther. 214, 592-598 (1981)

3 Bonnet, J.J., Lemasson, M.H. and Costentin, J.: Simultaneous evaluation by a double labelling method of drug-induced uptake inhibition and release of dopamine in synaptosomal preparation of rat striatum. Biochem. Pharmacol. 33, $2129-2135$ (1984)

4 Green, A.L. and El Hait, M.A.S.: Inhibition of mouse brain monoamine oxidase by $(+)$-amphetamine in vivo. J. Pharm. Pharmacol. 30, 262-263 (1978)

5 Stcin, W.D.: The Movement of Molecules Across Cell Membranes. p. $129-157$, Academic Press, New York (1967)

6 Bönisch, H. and Trenderenburg, U.: The mechanism of action of indirectly acting sympathomimetic amines. In Handbook of Experimental Pharmacology, Vol. 90/I, Catecholamines I, Edited by Trendercnhurg, U. and Weiner, N., p. 247-277, Springer-Verlag. Berlin (1988)

7 Hasebe, Y., Ono, H., Fukuda, H., Ohta, S. and Hirobe, M.: Enhancement of spinal reflexes with phenylethylamine and related drugs through descending noradrenergic neurons. J. Pharmacobiodyn. 12, $241-245$ (1989)

8 Hasebe, Y., Ono, H., Fukuda, H., Ohta, S. and Hirobe, M.: The most desirable conformation of phenylethylamine (PEA) moiety stimulating noradrenergic neurons: Effects of PEA, methamphetamine, phenelzine, methylphenidate, nomifensine and mazindol on rat spinal reflexes. Gen. Pharmacol. 20, $375-379$ (1989)

9 Ono, H., Hasebe, Y., Satoh, M., Nagao, T., Ohta, S., Hirobe, M. and Fukuda, H.: Amphetamine-antagonistic properties of 4-phenyl-1,2,3,4-tetrahydroisoquinoline: Inhibition of spinal reflex-enhancing effects of methamphetamine, phenylethylamine and nomifensine. Brain Res. 564, 319-322 (1991)

10 Ono, H., Ito, H. and Fukuda, H.: 2-Phenylethylamine and methamphetamine enhance the spinal monosynaptic reflex by releasing noradrenaline from the terminals of descending fibers. Japan. J. Pharmacol. 55, $359-366$ (1991)

11 Bjorklund, A. and Skagerberg, G.: Descending monoaminergic projections to the spinal cord. In Brain Stem Control of Spinal Mechanisms, Edited by Sjolund, B. and Bjorklund, A., p. 55-88, Elsevier Biomedical Press, Amsterdam (1982)

12 Strahlendorf, J.C., Strahlendorf, H.K., Kingsley, R.E., Gintautas, J. and Barnes, C.D.: Facilitation of the lumbar monosynaptic reflexes by locus coeruleus stimulation. Neuropharmacology 19, 225-230 (1980)

13 Westlund, K.N., Bowker, R.M., Ziegler, M.G. and Coulter, J.D.: Noradrenergic projections to the spinal cord of the rat. Brain Res. 263, 15-31 (1983)

14 Hirayama, T., Ono, H. and Fukuda, H.: Effects of adrenergic agents on ventral hom cells in rat spinal cord slices. Biomed. Res. 9, 343-351 (1988)

15 Hirayama, T., Ono, H. and Fukuda, H.: Functional supersensitivity of $\alpha$-adrenergic system in spinal ventral horn is due to absence of an uptake system and not to postsynaptic change. Brain Res. 539, 320-323 (1991)

16 Ono, H., Hasebe, Y., Satoh, M., Nagao, T., Ohta, S., Hirobe, M. and Fukuda, H.: 4-Phenyl-1,2,3,4-tetrahydroisoquinoline: A candidate for an antagonist to noradrenaline-releasing effects of amphetamines. Eur. J. Pharmacol. 183, 447 $(1990)$

17 Stamford, J.A., Kruk, Z.L. and Millar, J.: Dissociation of actions of uptake blockers upon dopamine overflow and uptakc in the rat nucleus accumbens: In vivo voltammetric data. Neuropharmacology 28, 1383 - 1388 (1989)

18 Heikkila, R.E., Orlansky, H. and Cohen, G.: Studies on the distinction between uptake inhibition and release of $\left[{ }^{3} \mathrm{H}\right]$ dopamine in rat brain tissue slices. Biochem. Pharmacol. 24, $847-852$ (1975)

19 Parker, E.M. and Cubeddu, L.X.: Comparative effects of amphetamine, phenylethylamine and related drugs on dopamine efflux, dopamine uptake and mazindol binding. J. Pharmacol. Exp. Ther. 245, 199-210 (1988) 